\title{
Desafios do enfermeiro diante da dor e do sofrimento da família de pacientes fora de possibilidades terapêuticas
}

\author{
NURSES' CHALLENGES IN VIEW OF THE PAIN AND SUFFERING OF FAMILIES OF \\ TERMINAL PATIENTS \\ DESAFÍOS DEL ENFERMERO ANTE EL DOLOR Y EL SUFRIMIENTO DE LA FAMILIA DE \\ PACIENTES FUERA DE POSIBILIDADES TERAPÉUTICAS
}

Maria de Fátima Prado Fernandes ${ }^{1}$, Janete Hatsuko Komessu ${ }^{2}$

\section{RESUMO}

O presente trabalho trata-se de um estudo de abordagem qualitativa com o objetivo de identificar os desafios dos enfermeiros para assistir às famílias de pacientes fora de possibilidades terapêuticas diante da dor e do sofrimento. A coleta de dados ocorreu no ano de 2008, mediante entrevista semiestruturada, com dezoito enfermeiros que trabalhavam em Unidades de Terapia Intensiva de um hospital privado localizado no município de São Paulo, após aprovação do Comitê de Ética em Pesquisa. Utilizou-se a análise de conteúdo para a avaliação dos dados. Obtiveram-se três categorias: enfrentando os desafios para assistir a família, posicionamento esperado e orientar-se a partir da experiência. Evidenciou-se que, para assistir às famílias, há necessidade dos enfermeiros refletirem a respeito dos valores pessoais e éticos, bem como sobre o processo do morrer. Espera-se que haja troca de experiências entre os enfermeiros já experientes com os que iniciam tal prática no âmbito do cuidar.

\section{DESCRITORES}

Cuidados de enfermagem

Estado terminal

Família

Dor

\section{ABSTRACT}

This qualitative study was performed with the objective to identify the challenges faced by nurses who assist families of patients with no hope of cure, in view of their pain and suffering. Data collection was performed in 2008 using semi-structured interviews, including eighteen nurses who worked in the Intensive Care Units of a private hospital located in São Paulo, after receiving approval from the Research Ethics Committee. The content analysis of the data revealed three categories: facing the challenges of assisting the family, expected attitude, and guiding yourself by experience. It was revealed that, in order to assist the families, nurses must reflect on their personal and ethical values, as well as examine their feelings regarding the process of dying. It is expected that experienced nurses will exchange their knowledge with those beginning their practice in this health care setting.

\author{
DESCRIPTORS \\ Nursing care \\ Critical illness \\ Family \\ Pain
}

\begin{abstract}
RESUMEN
Estudio cualitativo que objetivó identificar los desafíos de los enfermeros para atender a las familias de pacientes sin posibilidades terapéuticas, ante su dolor y sufrimiento. Datos recolectados en 2008, mediante entrevista semiestructurada, realizada a dieciocho enfermeros que trabajaban en Unidades de Terapia Intensiva de un hospital privado del municipio de São Paulo, luego de conseguirse la aprobación del Comité de Ética en Investigaciones. Se utilizó análisis de contenido para evaluar los datos. Los mismos determinaron tres categorías: Enfrentando los desafíos para atender a la familia, Postura esperada y Orientarse a partir de la experiencia. Se demostró que, para atender a las familias, existe necesidad de reflexión por parte de los enfermeros respecto de los valores personales y éticos, así como sobre el proceso del morir. Se espera que haya intercambio de experiencias entre los enfermeros con trayectoria y aquellos que inician su práctica en este ámbito del cuidado.
\end{abstract}

\section{DESCRIPTORES}

Atención de enfermería

Enfermedad crítica

Familia

Dolor

\footnotetext{
${ }^{1}$ Professora Doutora do Departamento de Orientação Profissional da Escola de Enfermagem da Universidade de São Paulo. São Paulo, SP, Brasil. fatima@usp.br ${ }^{2}$ Mestre em Enfermagem pela Escola de Enfermagem da Universidade de São Paulo, São Paulo, SP, Brasil. janetenakamura@usp.br

$\begin{aligned} & \text { Rev Esc Enferm USP } \text { Recebido: 19/04/2012 } \\ & \text { 2013; 47(1):250-7 } \text { Aprovado: 10/09/2012 } \\ & \text { www.ee.usp.br/reeuspl } \text { Português / Inglês } \\ & \text { www.scielo.br/reeusp }\end{aligned}$
}




\section{INTRODUÇÃO}

O assistir a família de pacientes fora de possibilidades terapêuticas é percebido como uma atividade difícil e complexa mesmo para o enfermeiro que tem experiência com pacientes críticos em risco iminente de morte e que por vezes se vê com dificuldades para assistir à família que se encontra em estado de dor e sofrimento. Mas parece ser muito mais complicado para o enfermeiro inexperiente e recém-formado que se inicia nessa prática.

Esse é um desafio constante para o enfermeiro que já tem experiência e muito mais para aquele que ainda não tem. Torna-se fácil compreender que proporção isso toma para o enfermeiro que inicia sua atuação profissional em unidades que assistem pacientes fora de possibilidades terapêuticas. Aqueles que já têm alguma experiência profissional apresentam mais recursos para enfrentar essa situação. Por outro lado, os que não têm podem se deparar com obstáculos, vivenciando problemas que já foram trabalhados em algum nível pelos enfermeiros experientes.

O cuidado dos familiares é uma das partes mais importantes do cuidado global dos pacientes internados nas unidades de terapia intensiva. É lamentável que o cuidado da família seja tão pouco abordado na maioria dos cursos de graduação da área da saúde. A literatura recente está repleta de evidências de que estratégias voltadas para os familiares, como a melhoria da comunicação, da prevenção de conflitos e do conforto espiritual, para citar algumas, resultam em maior satisfação e percepção da qualidade da assistência prestada ao paciente na UTI(1).

É difícil para as escolas trabalhar essa questão, pois os estudantes ainda não se encontram amadurecidos, principalmente no aspecto emocional. Isso é possível acontecer mediante o desenvolvimento do exercício profissional ou experiências de vida ante o processo do morrer.

Nessa direção, as autoras deste estudo consideram o quanto seria salutar se os enfermeiros pudessem expressar o que têm de mais significativo ao assistirem famílias de pacientes fora de possibilidades terapêuticas, diante da dor e do sofrimento, e que pudessem conversar com os enfermeiros pouco experientes a fim de os ajudar a refletir acerca de como assisti-las.

Estudos realizados estabeleceram o modo de olhar para a pessoa diante do processo da vida e da morte, valorizando as cinco etapas de reações por parte das pessoas sem esperança de vida ${ }^{(2-4)}$. Dos sentimentos em relação à morte emergem alguns elementos, que são: indiferença, tristeza, impotência e medo de expressar sentimentos e culpa ${ }^{(5)}$.
Assim como os demais profissionais da saúde, os enfermeiros devem buscar estratégias para melhor assistir à família, permanecendo a seu lado em momentos de grande angústia ${ }^{(6)}$. Ter ciência de que a família, dentro do possível, deve continuar a manter o trabalho e as funções familiares e sociais. Também deve manter sua identidade e, aos poucos, começar a reconhecer a identidade e a estrutura familiar sem o paciente terminal ${ }^{(7)}$.

Diante dessa situação, o enfermeiro deve estudar sobre aspectos que se reportam à família, uma vez que para elas ocorre uma perda, uma única perda que atinge muitas vidas, ou seja, a da própria família, de amigos, colegas de trabalho e profissionais de saúde que cuidam dos pacientes ${ }^{(8)}$.

Nesse sentido, torna-se imprescindível que o enfermeiro que inicia sua prática de assistir à família de pacientes fora de possibilidades terapêuticas seja acompanhado pelo enfermeiro mais experiente. Pois, embora os enfermeiros recém-formados tenham competência técnica e conhecimentos na esfera científica, ainda necessitam aprender a lidar com algumas questões que apontam dilemas éticos no processo de morte e morrer, vinculados à relação entre o enfermeiro e a família.

Os enfermeiros com experiência devem ter ciência que prover o cuidado à família exige conhecimentos que vão além do saber técnico. Os princípios éticos agregados aos valores individuais e coletivos nortearão as ações do enfermeiro, transformando a cada dia o significado do cuidar, sobretudo aqueles associados ao atendimento à família diante da dor e sofrimento. Essas premissas estão muito presentes para o profissional que começa a cuidar dessas famílias, pois as crenças acerca do processo do morrer ainda são muito fortes e acabam afetando o processo de assistir.

A partir das representações individuais é possível conhecer os pensamentos, as ações e os sentimentos acerca da morte e do morrer no âmbito coletivo, identificando os conceitos que determinam o comportamento e o enfrentamento, os medos e as crenças ${ }^{(5)}$. Esse enfoque torna-se real perante o processo do morrer e, ao cuidar da família, o enfermeiro depara-se com valores e histórias de vida que assinalando a possibilidade de diferentes modos de com ela interagir. Ao assistir as famílias, os profissionais de enfermagem acabam sendo influenciados por suas concepções, valores e experiências em relação à morte e ao morrer e, nessa condição, precisam trabalhar suas emoções.

O enfermeiro necessita aprender a se relacionar e também colocar em prática sua vontade, mediante a fala, os atos e as escolhas ${ }^{(9)}$. As vivências do enfermeiro em face da assistência às famílias de pacientes fora de possibilidades terapêuticas devem ser construídas com amorosidade e ética e não apenas sofrimento e dor e essa experiência deve ser compartilhada com os pares. 
Os profissionais da saúde apresentam maior proximidade com a morte, exigindo-se deles preparo e aperfeiçoamento para atendimento desses pacientes e de seus familiares ante a dor e o sofrimento ${ }^{(10)}$. A dor e o sofrimento são sentimentos distintos e componentes da existência humana e não é possível ter o direito de não sofrer.

Assim, cabe aos profissionais de saúde aliviar a dor, seja no aspecto orgânico ou psíquico. A dor é gerada por alguma situação que desencadeou fortes emoções negativas e nem sempre é compartilhada, gerando desconforto e caracterizando-se como um processo desfavorável para a mudança imediata desse sentimento(11). Por isso, a família leva algum tempo para aliviar e transformar esse sentimento. Em geral, a angústia presente distancia a família da possibilidade de ter outra ação mais positiva e o enfermeiro deve preparar-se para ajudá-la nesse momento.

Diante da assistência à família, o enfermeiro deve abrir espaços de reflexão com outros profissionais sobre o processo do morrer e permitir-se a mudar alguns padrões de conduta. O modo como o enfermeiro processa os meios e os recursos para atender à família no momento da dor e do sofrimento irá refletir no cuidado.

É desejável que o enfermeiro com experiência ajude os novos enfermeiros a cuidar das famílias de pacientes fora de possibilidades terapêuticas, mantendo compromisso, autonomia e postura ética, correlacionando-os aos limites e às possibilidades de intervenção diante do assistir. Neste estudo, pretendeu-se investigar como os enfermeiros que têm experiência com o assistir famílias de pacientes fora de possibilidades terapêuticas podem contribuir para que enfermeiros sem habilidades específicas nesta área do conhecimento possam vir a desenvolver essa prática.

A pesquisa teve como objetivo identificar como o enfermeiro, a partir de sua experiência em assistir a família de paciente fora de possibilidades terapêuticas, diante de sua dor e sofrimento, pode ajudar enfermeiros inexperientes e recém-formados a iniciarem a sua prática profissional neste contexto.

\section{MÉTODO}

Trata-se de um estudo exploratório e descritivo com abordagem qualitativa, realizado em um Hospital Privado localizado no Município de São Paulo.

Foram entrevistados 18 enfermeiros que trabalhavam em Unidades de Terapia Intensiva. O número de sujeitos foi determinado pela repetição das falas, ou seja, saturação.

A idade média dos 18 enfermeiros foi de 37 anos, com variação entre 27 a 53 anos, sendo apenas um do sexo masculino, e o tempo médio de experiência em assistência à família do paciente grave era de 11 anos. Todos tinham curso de especialização, sendo que quatro eram mestres, dois mestrandos e dois doutorandos.
Como critério de inclusão, considerou-se: ter experiência mínima de dois anos como enfermeiro de Terapia Intensiva na assistência à família de pacientes fora de possibilidade terapêuticas. Esse critério é importante, pois os enfermeiros que têm experiências em assistir às famílias de pacientes fora de possibilidades terapêuticas são os que acompanham aqueles que iniciam sua atuação profissional no cuidado à família diante da dor e sofrimento. Desse modo, têm muito a contribuir para o desenvolvimento dos iniciantes, mediante o processo de capacitação em campo da prática, frente à realidade da dor e sofrimento da família.

A indagação norteadora deste estudo foi: Como você orientaria o enfermeiro inexperiente ou recém-formado para assistir às famílias de pacientes fora de possibilidades terapêuticas, diante da dor e do sofrimento, considerando os desafios inerentes a essa situação?

A obtenção dos dados somente foi realizada após aprovação pelo Comitê de Ética e Pesquisa da Instituição (Parecer no 28/07), os dados foram coletados entre março e maio de 2008, por meio de entrevistas semiestruturadas que foram agendadas e gravadas em áudio, após a assinatura do Termo de Consentimento Livre e Esclarecido (TCLE), preservando o anonimato e respeitando linguagem utilizada pelos sujeitos na entrevista.

Para a compreensão dos depoimentos, os dados foram analisados conforme a técnica de análise de conteúdo, em três fases: pré-análise (leitura flutuante e preparação dos dados), exploração do material (considerou a exclusão mútua, homogeneidade, pertinência, objetividade, bem como produtividade) e tratamento dos resultados, inferência e interpretação(12).

As estruturas do conteúdo foram feitos recortes em unidades de contexto e registro, por meio de análise e seleção das frases presentes nos discursos, as quais expressaram sentido e consonância com objeto de estudo. Em seguida, houve a agregação dos temas, alcançando a representação do conteúdo. Assim, por meio dos discursos dos enfermeiros obtiveram-se as seguintes categorias: 1 ) enfrentando os desafios para assistir à família, 2) posicionamento esperado e 3 ) orientar-se a partir da experiência.

\section{APRESENTAÇÃO E ANÁLISE DOS DADOS}

Com os discursos submetidos à análise, constatou-se que houve aproximação quanto às experiências dos enfermeiros no que se refere ao confronto com a morte. Ao se posicionarem, os enfermeiros fizeram alusão sobre os possíveis desafios para assistir à família, apontando posturas profissionais esperadas. Colocaram o quanto a vivência em assistir às famílias com dor e sofrimento é considerada um fator importante para orientar os profissionais, incluindo os que iniciam sua atuação profissional diante dessa situação, principalmente pelo fato da formação 
acadêmica do enfermeiro, no que tange à assistência às famílias de pacientes fora de possibilidades terapêuticas, ser considerada insuficiente frente à complexidade do cuidar, devendo valorizar a experiência dos colegas.

\section{1) Enfrentando os desafios para assistir à família}

Para assistir as famílias de pacientes fora de possibilidades terapêuticas, exige-se do profissional de saúde que, além de obter conhecimentos sobre o processo do morrer, também aprenda a enfrentar seus medos. Ainda, que reflita acerca de sua filosofia de vida e seus valores pessoais e éticos, bem como conheça as diversas culturas religiosas que o ajudarão a entender as reações humanas frente à situação de perda iminente. É desejável ainda que estude outras ciências para melhor atender às necessidades apresentadas pelas famílias que apresentam dor e sofrimento.

Outro desafio é conseguir trabalhar com as necessidades espirituais das famílias ou prover espaço para que estas sejam atendidas. Para o entendimento da dor espiritual, pode-se considerar que espiritualidade pode ser definida como aquilo que traz significado e propósito à vida das pessoas. Transcender é buscar significado e a espiritualidade é um dos caminhos vivenciados pelas famílias ${ }^{(13)}$.

Diante da dor espiritual é comum as famílias recorrerem à fé como fonte de ajuda, buscando na religião o significado da vida e da morte. Por isso a assistência espiritual de acordo com suas crenças é considerada como gesto de amor e compreensão por eles ${ }^{(14)}$.

\section{As falas abaixo retratam essas questões:}

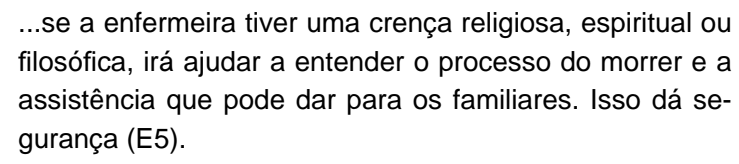

Foi referido que o enfermeiro, ao ter uma crença religiosa, poderá ajudar a família, que também apresenta suas crenças e valores espirituais, devendo ser assistidas ante sua angústia e temor. Essa postura que nem sempre é manifestada pelas enfermeiras, principalmente aquelas que não apresentam experiências.

\section{...na graduação, fala-se somente da parte legal, mas não como é trabalhar com a família. Na especialização, foi fa- lado um pouco mais, mas não se consegue aplicar. Ora, ninguém fala como é, como se deve agir com o familiar e isso faz falta (E9).}

É muito preocupante para o enfermeiro com experiência saber que o enfermeiro novo quase sempre vem sem preparo para cuidar da família e muitas vezes se vê sozinho nessa situação, sem receber ajuda de outros profissionais.

... a enfermeira recém-formada tem sua base... ela pode ter medo da morte. Por ter medo, ela não vai enfrentá-la.
Ela deve enfrentar isso, refletindo a respeito do processo do morrer... e adquirir outras atitudes (E5).

Ainda hoje é muito desconfortável para o enfermeiro sem a vivência da perda e/ou experiência cuidar da família que apresenta sofrimento. Mais difícil ainda é querer cuidar e não saber como fazê-lo. A insegurança é originada pela falta de conhecimentos, sejam na esfera acadêmica ou no próprio cotidiano do trabalho assistencial.

Nas escolas de Enfermagem, é muito comum o estudante demonstrar medo. Autores citam uma fala que reflete essa angústia

a aluna demonstra seu desconforto com a morte no cotidiano de estágio e se recusa a aceitá-la. A negação surge como uma capa que a protege do seu medo da morte, e, inconscientemente, busca fugir da morte ou de algo a ela relacionado... ${ }^{(15)}$.

se eu tivesse que dar instruções para a enfermeira, eu estaria falando primeiramente para ela se colocar no lugar da família que está perdendo um ente querido.... Nós profissionais temos que entender que o processo do morrer faz parte do ciclo da vida... mas fomos preparadas para fazer a manutenção da vida. Então, é muito difícil você assistir alguém que está morrendo (E8, E10).

A proximidade com a dor e o sofrimento parecem provocar nos enfermeiros uma empatia importante para o vínculo terapêutico, o que proporciona uma melhor assistência de Enfermagem, mas ao mesmo tempo um desgaste emocional íntimo ligado à dificuldade no lidar com a terminalidade ${ }^{(16)}$.

Assistir a família significa que o enfermeiro depara-se com questões que vão ao encontro de sua própria filosofia de vida e seus valores pessoais. Ao se aproximar das famílias, deve compreender que o cuidar envolve competências ontológicas, essenciais à maturidade e à sobrevivência da Enfermagem $^{(17)}$, que advém dos fatos que acontecem no cotidiano do cuidar de famílias diante da dor e sofrimento.

...quando você vê uma família que está enfrentando essa situação, tanto ela como nós sabemos o que vai acontecer no final do processo. Não tem como escapar disso e a gente não tem o preparo para dar esse suporte para a família (E10).

A fala acima reflete a presença de consciência do enfermeiro que percebe que não se encontra preparado para dar apoio à família. Por outro lado, ele tampouco recebe apoio da instituição onde trabalha e sente dificuldades para oferecer suporte emocional às famílias.

... se a enfermeira tiver medo ou dúvida o cuidado, vai ser sempre superficial. Ela não estará ao lado do familiar. Vai agir conforme as normas do hospital e não vai realmente atender à família na sua totalidade... (5).

Essa conduta que pode causar desconforto a família. Os familiares geralmente expressam estresse emocional ao se aproximarem da perda, principalmente com a falta de informações específicas sobre a evolução provável 
e conhecimento concreto da situação ${ }^{(18)}$. O enfermeiro experiente deve manter a família informada e ainda repensar em suas posturas para assistir adequadamente as famílias no processo de perda e dor.

...ajudar o recém-formado a pensar no cuidar para que paciente não sofra... mostrar isso para a família da melhor maneira possível (E15).

....eu acho que talvez possa ser dado um enfoque maior de treinamento, pode ser que isso auxilie um pouco a enfermeira (E3).

Prover treinamento depende de como este será processado e ainda não será suficiente. O enfermeiro deverá ajudar na formação do enfermeiro menos experiente para que este consiga assistir à família. Pois a família do paciente que se encontra fora de possibilidades terapêuticas, expressa sua dor como uma experiência única que depende de sua história de vida e dos laços que construiu com o ente querido. Nesse momento, o profissional pode ajudá-la melhor se entender a sua história.

O enfermeiro recém-formado tem o desafio de manter o diálogo com a família e, ao mesmo tempo, manter a sustentabilidade nos momentos de dar apoio. Também apresenta necessidades emocionais e de ajuda para realizar a intervenção ${ }^{(19)}$.

Todas as falas refletem a presença do medo, a dificuldade de transpor o saber teórico para a prática, sobretudo sem ter tido tempo e preparo consolidado para assistir as famílias no momento de angústia e dor. É desejável que haja espaço de diálogo entre a equipe de Enfermagem para que os mais experientes possam contribuir para o crescimento de todos.

\section{Posicionamento esperado}

Outro desafio para o enfermeiro experiente ou inexperiente que se propõe a cuidar do outro é entender que a família espera que tenha competência no desempenho de seu papel ${ }^{(20)}$. Por isso, espera-se que o enfermeiro adquira conhecimentos, habilidades e atitudes aliados a seus valores pessoais e éticos e apresente um agir profissional adequado à situação de atendimento à família do paciente fora de possibilidades terapêuticas.

Em razão da falta de amadurecimento e possivelmente pela necessidade de atingir as expectativas de seus pares, algumas enfermeiras que iniciam essa prática só se preocupam em dar as informações a essas famílias, restringindo seu papel profissional. Espera-se que o profissional exerça sua função com equilíbrio e eficiência, passando por um período de aprendizado, recebendo o apoio da instituição onde atua ${ }^{(21)}$.

As falas abaixo evidenciam o posicionamento esperado das enfermeiras inexperientes.

...eu acompanhei uma enfermeira recém-formada e a fa-

mília do paciente tinha uma série de questionamentos a respeito de quais condutas seriam tomadas... a enfermeira se preocupava muito de falar da técnica, dizer o que estava sendo feito com o paciente, mas a família não queria saber se estava com drogas vasoativas e sim se ele estava confortável (E1).

Para o enfermeiro que assiste a família do paciente fora de possibilidades terapêuticas é muito difícil compreender o que esta quer Ihe falar em face da dor que sente. Uma postura fundamental é tentar ouvi-la, saber o que ela precisa e não julgar suas prioridades no momento ${ }^{(16)}$.

\begin{abstract}
...a enfermeira recém-formada se sente pressionada com a situação, se sente amedrontada e a relação se torna muito mecânica, prevalece a preocupação somente em dar informações. Eu diria que se deve estar mais próximo à família para perceber suas necessidades e tentar supri-las (E1).
\end{abstract}

\section{A família necessita receber informações}

... falta de divulgação da informação para os familiares sobre as reais condições do paciente e sobre as estratégias diagnósticas e terapêuticas utilizadas é queixa freqüentemente elaborada por eles. A informação deve ser fornecida aos poucos e repetida várias vezes ao dia, sempre com o mesmo enfoque...(22).

Autores explicitam que cuidar do familiar significa compreender as suas emoções, os seus gestos e falas, seus conceitos e limitações ${ }^{(23)}$.

...dizer para a enfermeira recém-formada que a enfermagem continua com os cuidados ao paciente mesmo que o prognóstico seja fechado pela equipe, como, por exemplo, alimentação, mudança de decúbito, higiene... e dar conforto para a família (E5; E4; E14).

A fala apresentada acima considera aborda a questão da necessidade dos familiares em saber que o ente querido encontra-se recebendo conforto, o que pode trazer alento a família.

As ações de enfermagem, em consonância com a equipe multidisciplinar, são orientadas a possibilitar e viabilizar a morte tranquila ao paciente ${ }^{(21)}$. Essa condição deve ser trabalhada junto aos familiares, respeitando seu tempo para trabalhar o processo de luto antecipatório.

...em primeiro lugar, ouvir o que a família tem para falar. Perceber o que a família acha da situação e sentir o que ela está esperando (E7; E18).

...oriento para conversar com a família, mas não é o que acontece no dia-a-dia. Então, penso como poderíamos melhorar isso (E11).

...tentar manter um diálogo o mais coerente possível com a família, não criando falsas expectativas em relação à situação (E12).

Evidencia-se a importância do contato direto do enfermeiro com o familiar que muitas vezes manifesta a necessidade da equipe de enfermagem de informar e explicar melhor o que está acontecendo com o paciente ${ }^{(24)}$. 
...cada família reage de um jeito diante do diagnóstico do paciente sem possibilidade de tratamento, não tem uma receita de bolo. Tem enfermeiras que conseguem conver-

sar e escutar a família (E13).

É necessário considerar a discussão multidisciplinar em relação aos objetivos do cuidado centrado no paciente e sua família. Ao mesmo tempo em que se busca minimizar o desconforto do paciente, procura-se maximizar a assistência à dor e ao sofrimento da família(25).

Ao ter consciência da possibilidade de morte de seu parente na UTI, a família sofre e deixa aflorar em sua mente as lembranças de morte de outras pessoas, as comparações entre sofrimentos vividos, a compreensão sobre a temática, o estabelecimento de novos objetivos, a revelação de dilemas antes não percebidos, apesar da busca de qualidade de vida e das atitudes do seu familiar crítico no enfrentamento da morte ${ }^{(26)}$.

No contato com os enfermeiros na UTI, a família tenta expressar sua dor de diversos modos e o profissional necessita desenvolver habilidades de comunicação. Este aspecto é considerado tão importante quanto a habilidade de avaliação e cuidado especializado ao paciente crítico nessa unidade ${ }^{(22)}$.

Estudos concluíram que, com frequência, os profissionais que atuam em UTI não estão preparados para ouvir e responder as questões de familiares, reconhecer suas emoções e explicitar cuidados como o não abandono e respeito ao paciente. Provavelmente isso ocorra por valorizar somente a tecnologia e o cuidado que envolve o paciente, na busca de resultados positivos na terapêutica clínica em detrimento ao cuidado da família ${ }^{(27)}$.

É importante escutar a família e também é esperado que o enfermeiro saiba quando e como responder suas indagações. Para isso este deve conhecê-la e manter-se próximo a ela numa atitude de respeito.

Familiares podem apresentar desconfortos decorrentes da vivência do processo do morrer, como a ansiedade, depressão e transtorno de estresse pós-traumático. Nessa situação, a intervenção deve ter foco na comunicação com as famílias, podendo ter efeitos significativos no intuito de minimizar estas consequências ${ }^{(28)}$.

\section{Orientar-se a partir da experiência}

Existe um grande desafio que é valorizar a própria experiência e também de outros profissionais que já cuidaram ou cuidam de famílias de pacientes fora de possibilidades terapêuticas. Não se está falando aqui do domínio da tecnologia no âmbito da saúde, mas da sensibilidade que o profissional necessita desenvolver para lidar com a família a partir de atitudes de acolhimento e atendimento de suas necessidades emocionais, sociais e espirituais. As falas abaixo reportam essa questão:
... orientar a família quanto à possibilidade de abrir mais 0 horário de visita se o paciente estiver fora de possibilidades terapêuticas (E2).

A equipe acaba por não perceber a necessidade de acolhimento ao familiar, que muitas vezes entra e sai da UTI no horário de visita sem receber a atenção que necessita para o enfrentamento da situação crítica de saúde do seu familiar ${ }^{(24)}$.

... eu falaria para a enfermeira dar conforto para a família e para o paciente (E4).

...eu falaria que é importante poder contar e falar abertamente para as pessoas da sua equipe a respeito das dificuldades na assistência à família... (E10).

Ressalta-se que a efetividade das ações de Enfermagem com a família na presença da dor e do sofrimento diante da perda iminente decorre de trabalho interdisciplinar, bem como do trabalho da equipe de Enfermagem que cuida do paciente e de seus familiares ao longo do processo de morte. Nesse processo, o diálogo é muito importante para ajudar profissionais e famílias.

Há escassez de publicações sobre a atuação do enfermeiro junto à família de pacientes adultos fora de possibilidades terapêuticas. Porém, o cotidiano das UTI revela famílias com necessidades de orientações e espaços para suprir suas necessidades emocionais e espirituais diante da perda iminente, além da presença de profissionais preocupados com o cuidado centrado nas famílias.

Neste estudo foi possível identificar que os enfermeiros ainda apresentam dificuldades para expressar totalmente como ajudariam os enfermeiros menos experientes a iniciar sua prática, visto que têm muita experiência. É possível que a participação neste estudo tenha levado tais enfermeiros a refletir de como vêm trabalhando com a dor e o sofrimento das famílias de pacientes fora de possibilidades terapêuticas.

Os posicionamentos dos enfermeiros do como assistir a essas famílias em face de sua dor e sofrimento ainda não se encontram totalmente delineado e há necessidade de maior preparo, inclusive dos que já lidam com esta situação em seu cotidiano de trabalho. Todos têm como desafio aprender a olhar para seus valores e crenças para melhor cuidar destas famílias diante da perda iminente. Avançar a partir daquilo que já foi vivenciado e daquilo que ainda não foi trabalhado de maneira compartilhada com seus pares, com a equipe interdisciplinar e principalmente com os próprios familiares.

\section{CONCLUSÃO}

Os enfermeiros que têm experiência de assistir às famílias de pacientes fora de possibilidades terapêuticas, diante de sua dor e sofrimento, necessitam dialogar com os menos experientes e os recém-formados que estão se 
iniciando nessa modalidade de cuidar, considerando que todos estão em processo permanente de aprendizagem.

A literatura em Enfermagem confirma que há lacunas na formação acadêmica dos enfermeiros para assistir às famílias de pacientes fora de possibilidades terapêuticas. Essa é uma tarefa difícil, pois cada família demanda atenção particularizada no cuidado diante de sua dor e sofrimento, muitas vezes de modo discreto, porém não menos premente e importante.

Este estudo mostrou que é possível identificar que os enfermeiros têm o que ensinar acerca do processo do cuidar de famílias diante de sua angústia, mas cabe ainda dimensionar como será feita essa abordagem. Claro que isso não é uma tarefa fácil, pois ainda há muitos desafios a serem trabalhados, como, por exemplo, o medo da morte. Há necessidade de constituir espaços para que haja diálogos construtivos e sinceros entre todos os envolvidos no processo.

Os resultados deste estudo apresentam as limitações de um estudo qualitativo, contextualizado no local e tempo da investigação, mas podem contribuir para orientar os

\section{REFERÊNCIAS}

1. Soares M. Cuidando da família de pacientes em situação de terminalidade internados na Unidade de Terapia Intensiva. Rev Bras Ter Intensiva. 2007;199(4):481-4.

2. Kübler-Ross E. Perguntas e respostas sobre a morte e o morrer. São Paulo: Martins Fontes; 1979.

3. Kübler-Ross E. Morte: estágio final da evolução. 2a ed. Rio de Janeiro: Record; 1996.

4. Kübler-Ross E. Sobre a morte e o morrer. São Paulo: Martins Fontes; 2000

5. Oliveira JR, Brêtas JRS, Yamaguti L. A morte e o morrer segundo representações de estudantes de enfermagem. Rev Esc Enferm USP. 2007;41(3):386-94.

6. Fernandes MFP, Freitas GF. Processo de morrer sob a ótica da ética. In: Oguisso T, Zoboli ELCP, organizadoras. Ética e bioética: desafios para a enfermagem e a saúde. Barueri: Manole; 2006. p. 153-69.

7. Oliveira MF, Luginger S, Bernardo A, Brito M. Morte: intervenção psicológica junto da família do paciente terminal. Portal Psicólogo [Internet]. Lusíada (PT): Universidade Lusíada; 2004 [citado 2004 nov. 24]. Disponível em: http://www.ufpel.tche. $\mathrm{br} /$ medicina/bioetica/IntervencaoPsicologicaJuntoaFamiliadoPacienteTerminal.pdf

8. Kübler-Ross E, Kessler D. Os segredos da vida. Rio de Janeiro: Sextante; 2004. enfermeiros, bem como professores da área da Enfermagem, em discussões e investigação sobre como assistir às famílias de pacientes fora de possibilidades terapêuticas, diante da sua dor e sofrimento.

Aprender a enfrentar as dificuldades para assistir à família um aprendizado contínuo, pois cada família é única, e, por ouro lado, às vezes, cada profissional nessa situação também pode ter condutas únicas. Os desafios do enfermeiro que inicia suas atividades profissionais são ainda maiores, pois no início pode ter resistências, sejam elas em nível estrutural, ambiental ou em relação ao despreparo para lidar com a dor e o sofrimento da família.

As orientações dadas por enfermeiros já experientes são válidas e necessárias. Neste estudo, os participantes enfatizaram a importância de aprender em como assistir à família diante da dor e sofrimento e que todos busquem conhecimentos. É desejável que reflitam sobre suas experiências e aprendam juntos a enfrentar os desafios inerentes à assistência à família em situação de perda.

9. Fernandes MFP, Freitas GF. Fundamentos da ética. In: Oguisso T, Zoboli ELCP, organizadoras. Ética e bioética: desafios para a enfermagem e a saúde. Barueri: Manole; 2006. p. 27-44.

10. Hennezel M, Leloup JY. A arte de morrer: tradições religiosas e espiritualidade humanista diante da morte na atualidade. Petrópolis: Vozes; 1999.

11. Tealdi JC. Diccionario latinoamericano de bioetica. Bogotá: Universidad Nacional de Colombia; 2008.

12. Bardin L. Análise de conteúdo. Lisboa: Edições 70; 2008.

13. Peres MFP, Arantes ACLQ, Lessa OS, Caous CA. A importância da integração da espiritualidade e da religiosidade no manejo da dor e dos cuidados paliativos. Rev Psiquiatr Clín (São Paulo). 2007;34 Supl 1:82-7.

14. Gutierrez BAO, Ciampone MHT. O processo e morrer no enfoque dos profissionais de enfermagem de UTI. Rev Esc Enferm USP. 2007;41(4):660-7.

15. Carvalho LS, Oliveira MAS, Portela SC, Silva CA, Oliveira $\mathrm{ACP}$, Camargo $\mathrm{CL}$. A morte e o morrer no cotidiano de estudantes de enfermagem. Rev Enferm UERJ. 2006;14(4):551-7.

16. Chaves AAB, Massarollo MCKB. Perception of nurses about ethical dilemmas related to terminal patients in Intensive Care Units. Rev Esc Enferm USP [Internet]. 2009 [cited 2011 Sept 14];43(1):30-6. Available from: http://www.scielo.br/ pdf/reeusp/v43n1/en_04.pdf 
17. Watson J. Nursing: seeking its source and survival [editorial]. ICU Nurs Web J [Internet]. 2003 [cited Dez 12]. Available from: http://www.ucdenver.edu/academics/colleges/ nursing/caring/caringinaction/documents/watsonicu02.pdf

18. Lazo TO, Santana SC, Dìaz TT. Atención al paciente en estado terminal y su familia. Rev Ciênc [Internet]. 2009 [citado ago. 25]. Disponible en: http://www.revistaciencias.com/ publicaciones/EEupIFEpFAmMcxCqrd.ph.p

19. Downey L, Engelberg RA, Shannon SE, Curtis JR. Am J Crit Care. 2006;15(6):568-79.

20. Goffman E. A representação do eu na vida cotidiana. Petrópolis: Vozes; 2007.

21. Susaki TT, Silva MJP, Possari JF. Identificação das fases do processo de morrer pelos profissionais de Enfermagem. Acta Paul Enferm. 2006;19(2):144-9.

22. Martins JJ, Nascimento ERP, Geremias CK, Schneider DG, Schweitzer G, Mattioli Neto H. O acolhimento à família na Unidade de Terapia Intensiva: conhecimento de uma equipe multiprofissional. Rev Eletr Enferm. 2008;10(4):1091101. Disponível: http://www.fen.ufg.br/revista/v10/n4/ v10n4a22.htm
23. Silva MJP, Baraldi S. Reflexões sobre a influência da estrutura social no processo da morte-morrer. Nursing (São Paulo). 2000;1(24):14-7.

24. Inaba LC, Silva MJP, Telles SCR. Paciente crítico e comunicação: visão de familiares sobre sua adequação pela equipe de enfermagem. Rev Esc Enferm USP. 2005;39(4):423-9.

25. Curtis JR. Caring for patients with critical illness and their families: the value of the integrated clinical team. Respir Care. 2008;53(4):480-7.

26. Lima AB, Santa Rosa DO. The life meaning of the parents of the critical patient. Rev Esc Enferm USP [Internet]. 2008 [cited 2011 Sept 14];42(3):547-53. Available from: http:// www.scielo.br/pdf/reeusp/v42n3/en_v42n3a18.pdf

27. Curtis JR, Engelberg RA, Wenrich MD, Shannon SE, Treece $\mathrm{PD}$, Rubenfeld GD. Missed opportunities during family conferences about end-of-life care in the intensive care unit. Am J Respir Crit Care Med. 2005;171(8):844-9.

28. Lautrette A, Darmon M, Megarbane B, Joly LM, Chevret $S$, Adrie $C$, et al. A communication strategy and brochure for relatives of patients dying in the ICU. N Engl J Med. 2007;356(5):469-78. 